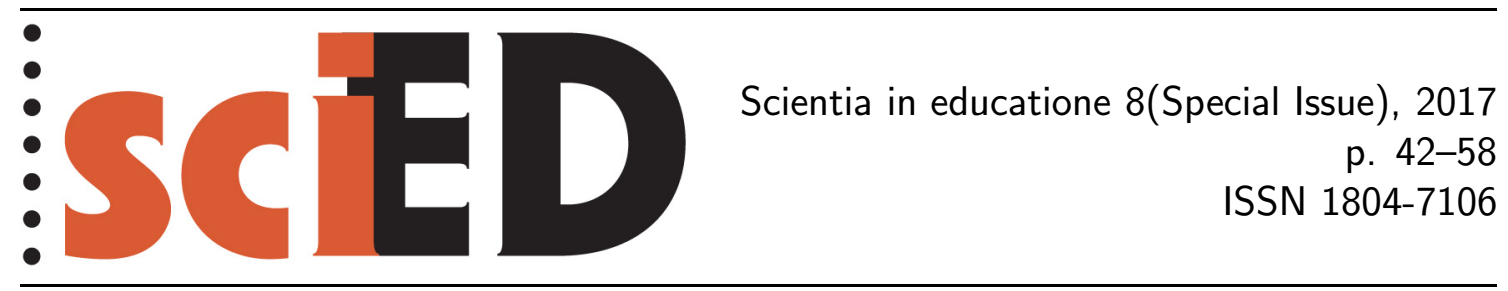

\title{
Active Learning in the Heureka Project Teachers in the Role of Students
}

\author{
Irena Dvoŕáková
}

\begin{abstract}
Our long-term Heureka project is based on the principle of active work in learning and teaching - both at school with students and in teacher training. Teachers in our seminars work the same way as students at schools - solving the same problems, doing the same experiments and sometimes even making the same mistakes. Our seminars provide longterm systematic training - the cycle of seminars for new participants takes ten weekends during the course of two years. That gives all participants the possibility and especially the time to change their approach to teaching physics.

The character of our seminars is rather informal: the seminars are free of charge and teachers join Heureka on a voluntary basis, gaining no formal advantages or benefits at their schools. The seminars take place during weekends, with teachers staying (and sleeping) in classrooms. In the autumn of 2012, we started already the 6th seminar cycle. Over the years, we have built a network of about 150 active teachers who have the possibility to meet at various advanced seminars and at "The Heureka Workshops" annual conference. The conference regularly attracts more than 100 participants and includes international guests.

We are convinced that our experience could be interesting and inspiring for other people working in physics education in different countries.
\end{abstract}

Key words: active learning, teachers training, The Heureka Project. 


\section{INTRODUCTION}

Do you know any teachers training -

- where participants are really active?

- which is organized during weekends and lasts two years?

- which is voluntary and free of charge?

- where participants are accommodated in school, sleeping in their sleeping bags in the classrooms?

- in spite of these non luxury conditions teachers come again and are keen in participating this project?

Do you know such teachers training? If yes, you maybe know (part of) The Heureka Project.

The following text concerns this project, its principles and methods. Several concrete examples of methodological sequences, many tasks and comments from my school work are presented. You can find here a detailed description of three lessons (concerning measurement of time), one labwork (weighing using a piece of a paper) and two tests. This text gives also the results of a research, where the scientific reasoning of students that attended the Heureka programme was evaluated. The second part of the article describes the teachers training programme that we organize since 2002.

\subsection{A FEW PERSONAL WORDS (THAT YOU CAN SKIP)}

Before describing The Heureka Project I would like to say something about my work, because the whole project reflects my long time experience from my school work. I am a lector at the Department of Physics Education at the Faculty of Mathematics and Physics, Charles University in Prague. Our department focuses on the preparation of future physics teachers, but organizes also many activities for students from secondary schools and for physics teachers. We also do research in physics education, authors of several textbooks work in our department, etc.

I am also a teacher. I have a part time job at a lower secondary school in Prague. I teach physics to children of ages from 12 to 15 years. For me being a normal teacher is very important. I know how today's children look like, I know the problems in real schools. When speaking with my students at the faculty, I can describe to them some real situations at school, give them examples from my school work. Moreover, my school gives us a good base for the Heureka seminars.

\subsection{Formation of The Heureka Project}

In the 90s, a group of about 5 people started finding ways to teach physics more actively and interestingly. For me it was very interesting to find, when working on my $\mathrm{PhD}$. thesis many years later, that this empirical approach has many similar characteristics to modern pedagogical approaches, like constructivism and IBSE.

At the beginning we focused only on work with children in my school. Gradually other teachers became interested in our method, wanted to join and teach using this method, so we started to organize weekend seminars for them and the main aim of the project changed to the teacher training. 


\section{The First Main Part of The Heureka PROJECT — WORK WITH CHILDREN}

The two following examples provide a good illustration of our approach.

\subsection{EXAmple of The MeThodologicAl SEQUENCE - MEASUREMENT OF TIME}

Children in the sixth class (about 13 years old) learn about measurement of the basic physical quantities (length, mass, temperature), and also time. We speak about different ancient clocks and then I tell children a story about Galileo and his investigation of pendulum. I ask children what properties the motion of pendulum could depend on. Children usually come up with many different properties:

- mass of the body

- shape of the body

- length of the string

- deflection at the beginning

- thickness of the string

Together we find that for an appropriate body, a thin string and small angles the motion of the pendulum depends only on its length. This investigation is a task for the next lesson.

For the next lesson I prepare a table for pupils' results. Children work in pairs. Their task is to measure the number of cycles per ten seconds for two different lengths of the pendulum. Each measurement is repeated twice. After measuring children fill in the table (Table 1).

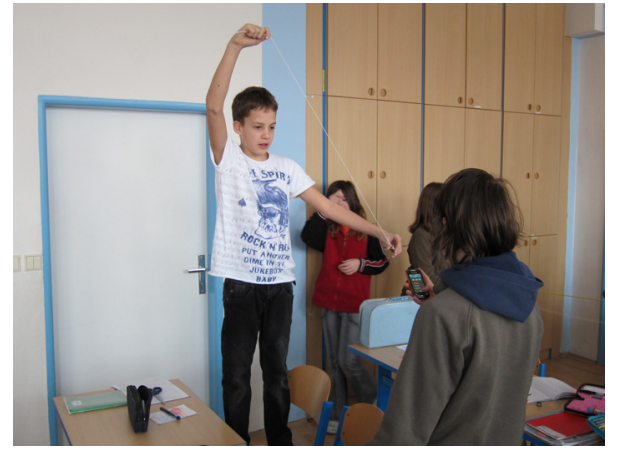

Figure 1: Measuring in the classroom

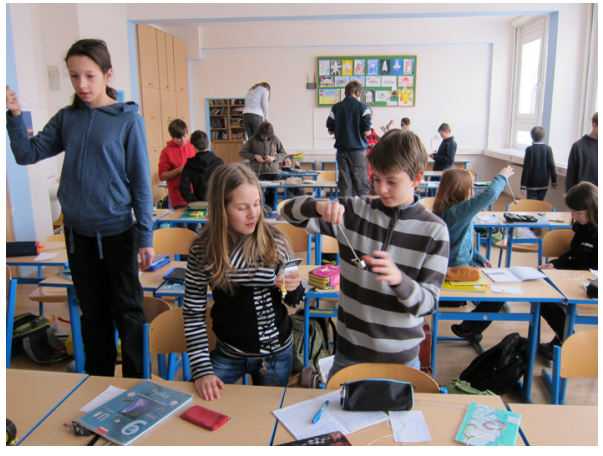

Figure 2: Measuring in the classroom

When all groups finish their task, children write the two important columns length and average number of cycles - in their exercise books. I give them a piece of millimetre graph paper and tell them that they have to draw a dot graph as homework. For most of the children this is the first graph ever they do in the school, so they need some hints. I show children how to start with two axes, discuss with them the scale on both axes, and how to find the point that corresponds to particular coordinates. I also tell them to draw only dots, not a curve. Children draw a graph at home. It is a hard task for them, but usually almost all of them are able to do it. At the beginning of the next lesson I check their work very quickly. Children correct their graph, if it is possible. 
Table 1: Example of the results of measuring the number of cycles of the pendulum per ten seconds for different lengths (children's results, age about 13, April 2012)

\begin{tabular}{ccccc}
\hline \multirow{2}{*}{ Group } & \multirow{2}{*}{ Length $\mathbf{( c m )}$} & Number of cycles per 10 s & \multirow{2}{*}{ Average } \\
\cline { 2 - 4 } A & 10 & $\mathbf{1 .}$ & $\mathbf{2 .}$ & \\
\hline B & 15 & 9 & 17 & 17 \\
\hline C & 20 & 9 & 10 & 9.5 \\
\hline D & 25 & 11 & 11 & 9.5 \\
\hline E & 30 & 9 & 9 & 11 \\
\hline F & 35 & 9 & 9 & 9 \\
\hline G & 40 & 8 & 8 & 9 \\
\hline H & 45 & 7.5 & 8 & 8 \\
\hline I & 50 & 7.5 & 7.5 & 7.75 \\
\hline J & 55 & 6 & 6 & 7.5 \\
\hline K & 60 & 7 & 7 & 6 \\
\hline L & 65 & 6 & 6 & 7 \\
\hline M & 70 & 7 & 7 & 6 \\
\hline A & 75 & 5.5 & 6 & 7 \\
\hline B & 80 & 6 & 6 & 5.75 \\
\hline C & 90 & 6 & 5.5 & 6 \\
\hline D & 100 & 5.5 & 5.5 & 5.75 \\
\hline E & 110 & 5 & 5 & 5.5 \\
\hline F & 120 & 5 & 5 & 5 \\
\hline G & 130 & 4 & 4 & 5 \\
\hline H & 140 & 4.5 & 4.5 & 4 \\
\hline I & 150 & 4 & 4 & 4.5 \\
\hline J & 160 & 4 & 4 & 4 \\
\hline K & 170 & 4 & 4 & 4 \\
\hline L & 180 & 4 & 4 & 4 \\
\hline M & 190 & 3.5 & 3.5 & 4 \\
\hline & & & & 3.5 \\
\hline
\end{tabular}

On the following figures you can see the expected result of the homework and the common wrong result, when a pupil did not listen to my hints and comments well.

Figure 3: Number of cycles per $10 \mathrm{~s}$ versus length - Expected result

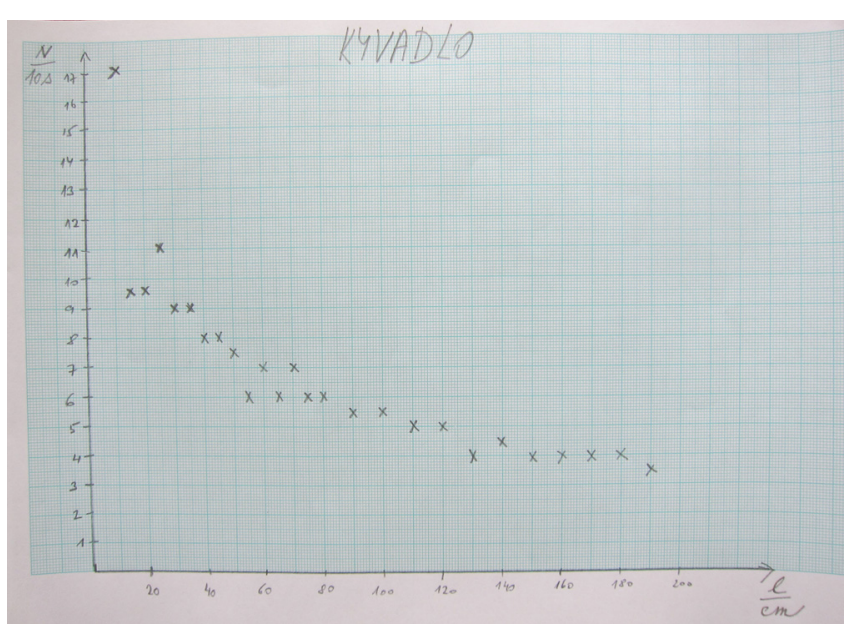


Figure 4: Example of a typical incorrect result

Figure 5: The curve showing how the number of cycles of the pendulum per ten seconds depends on the length (measured data)
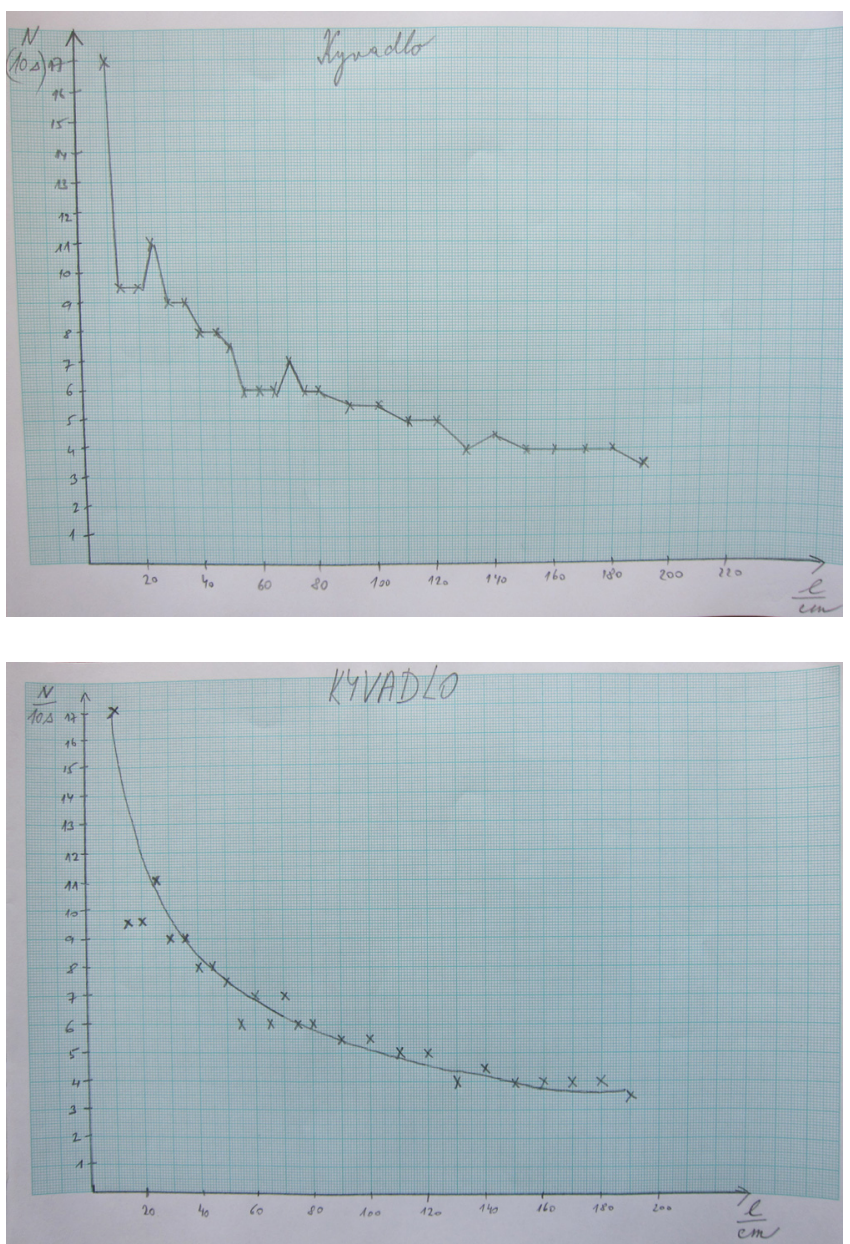

After checking the homework I tell children - take a pencil and draw a curve free hand, i.e. the curve, which roughly passes through the dots. Children are first very surprised, but in the end they draw something like this (see Figure 5).

Then I show children the precise graph with calculated values and we compare both graphs. I don't tell children "the formula"; I only tell them that the graph is made using a mathematical expression.

\section{Pendulum}

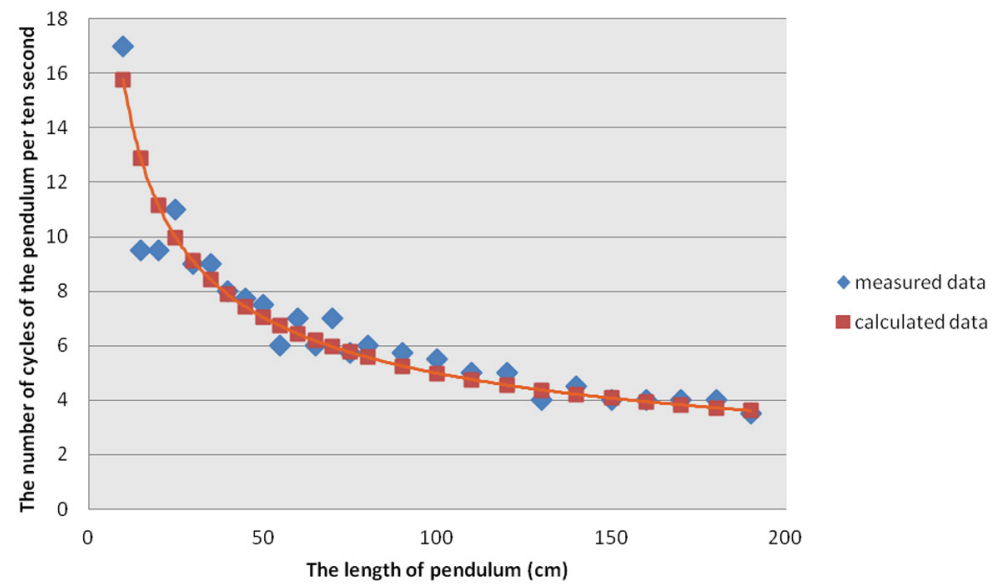

Figure 6: The graph shows both measured and calculated data

We discuss what the graph tells us. Children answer different questions like You have a pendulum which is $32 \mathrm{~cm}$ long, could you find its number of cycles per 10 seconds? How long should a pendulum be which is ticking each second?

At the end of this lesson we speak about the function of a pendulum in mechanical clocks. 


\subsection{Comments on the methodological Sequence MEASUREMENT OF TIME}

When speaking about this approach, the first question teachers give me usually is "Why do you measure the number of cycles per ten second, instead measuring its period? It would be certainly easier for children and more precise." The answer is simple. Imagine how a period of pendulum depends on its length. In case we measure a period, the result will be a different curve (see Figure 7). In this case all children would use a ruler and draw a straight line. It would be hard to persuade them that this is not a straight line.

Figure 7: The period/length dependence graph

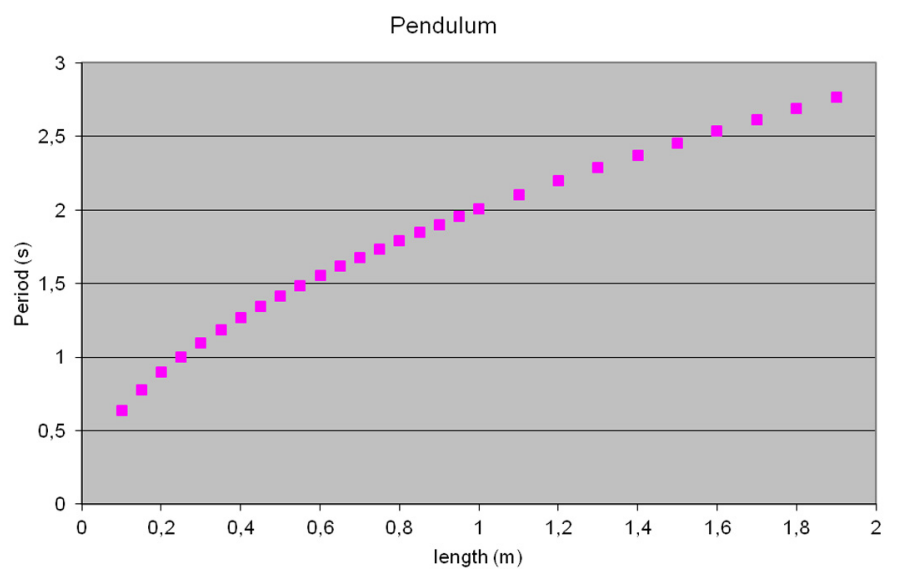

I must say I consider this sequence to be one of the most important topics in the 6th grade. In the first year of learning physics, children are able to work really like physicists - they formulate the hypothesis, verify it, collect real data, work with them, draw a non-linear graph, discuss this graph, read information from it, compare measured and calculated results, etc. Children will use all these skills (or competencies) during their entire physics studies. Moreover, I use another task concerning pendulum as a lab work in the ninth grade, so children can apply their findings in a different situation several years later. This is the reason I spent three lessons on such a seemingly trivial problem like the principle of a pendulum.

\subsection{EXAMPle OF A WRITTEN TEST}

My second example is a test:

\section{WRItTEN TEST IN THE 7TH GRADE - OCtOBER 2012}

1. A child is on a merry-go-round (carousel). What should the child do and how should the merry-go-round behave to accomplish the following situations:

a) the child is at rest with respect to the merry-go-round and in motion with respect to the Earth,

b) the child is in motion with respect to the merry-go-round, at rest with respect to the Earth,

c) the child is in motion with respect to the merry-go-round and to the Earth too

d) the child is at rest with respect to the merry-go-round and with respect to the Earth too. 
2. A motorboat has a speed of 20 metres per second and it takes it 40 min to travel the distance between two ports. How far are the ports? How long does this journey take for a slower boat, which goes at a speed of $10 \mathrm{~km}$ per hour?

3. The bus went 0.5 hours at a speed of $50 \mathrm{~km}$ per hour, then the next $20 \mathrm{~km}$ it went at $40 \mathrm{~km}$ per hour, then it stood still for half an hour. Then it covered the remaining $100 \mathrm{~km}$ at a speed of $50 \mathrm{~km}$ per hour. Calculate how many kilometres it covered in total and how long it took (including the rest). Calculate the average speed of this motion.

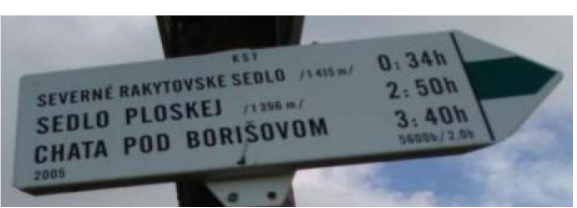
Draw a graph showing the distance-time dependence.

4. You can see a photo of a guidepost on which distances are given in hours, not in kilometres. Explain in which regions it is used and the reason for it.

5. Design some processes, the speed of which makes sense to measure in: a) cm per hour, b) litre per minute, c) kg per year, d) mm per year.

6. Write a story to the graph:

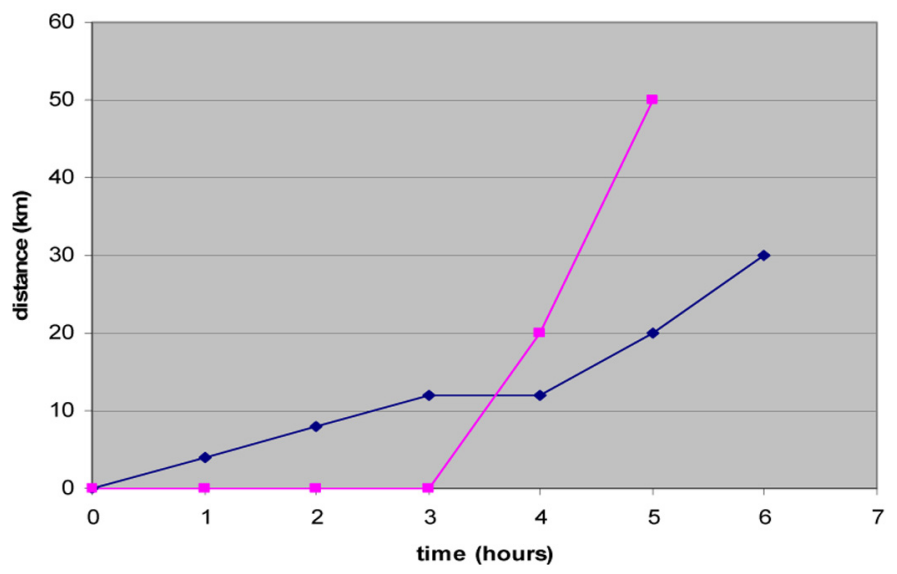

\subsection{COMMENTS ON THE TEST}

As you can see the first three tasks are common tasks you can find in all collections of problems. The tasks number four and five require children to apply their knowledge in a new situation; they did not solve similar tasks before the test.

I would like to emphasize the last task. Children have to think about what bodies probably move (according to their velocity), how their movement looks like, and, moreover, to create a simple story. In my experience this type of tasks is interesting for children for example as a voluntary homework, too. Children like it very much and their stories are very pretty.

Grading this type of exam is not easy for teacher. It is necessary to understand students' ideas, which are sometimes a bit complicated. But my goal is to develop students' thinking, so my tests must require thinking, too.

One important comment: Sometimes teachers who do not teach according to Heureka want to use my tasks. I usually tell them "Be careful. It is not fair to give those tasks to your students in case you use a traditional teaching approach. You cannot require students' thinking in a test, if you do not require their thinking in lessons." 


\subsection{The BASIC PRINCIPLES OF THE HeUREKA APPROACH}

As I said before, the basic principles of The Heureka Project are in agreement with many modern trends in physics education worldwide, in spite of the fact that the authors arrived at these principles independently. The authors had no connection with pedagogical research at that time, because until the early 1990's it was very difficult in the Czech Republic to obtain foreign pedagogical literature.

The most important of these principles include:

- A high rate of student/teacher interaction.

- An inquiry-based approach to teaching.

- Nature is the final authority, not the words of the teacher.

- Mistakes are normal and an important part of the learning process.

- The starting point of teaching and learning is a question and observation.

- The specific physical terms are defined at the end, after observation of experiments and description all important properties.

- We start from things that children know from everyday life.

- Students are not merely passive "objects of education," but are led to think about problems, formulate hypotheses and use experiments to verify them.

I hope at least some of these basic principles are visible in my previous examples.

\subsection{IS THERE SOME REAL IMPACT OF THE HEUREKA APPROACH ON THE THINKING ABILITIES OF STUDENTS?}

This is a question I was already interested in, but I had no ways how to measure it, until I learned about a Lawson's test of scientific reasoning several years ago. This test is based on Piaget's research; it is able to measure concrete- and formaloperation reasoning. It consists of 12 pairs of items. An item is scored correct only if the correct answer is checked and also an adequate explanation is given. The maximum number of points is 24 . You can find the ideas of the test, its methods and results in articles (Lawson, 1978a, 1978b, 1984, 1985; Renner, 1993; Dewey, 2011), it is not the topic of this article. For me it was important that it is possible to use the test for determining the developmental levels of my students. I found that this is a method which allows me to measure students' abilities.

I decided to test my students at the end of attendance at our school. You can see the results of my students since 2010 to 2013 in Table 2. The next idea was to compare the results of students who learned according to The Heureka Project with students who are not taught according to Heureka. I asked my colleagues who use the Heureka approach and several teachers who do not use this approach to test their students. The age of my students and other students in "the Heureka group" was 15-16 years, the age of students in the control group was 15-18 years. Table 3 shows the total results, Table 4 shows the distribution of students on developmentalreasoning levels described in Piaget's research. The same results are also shown in graphs (see Figure 8 and Figure 9). Though this does not represent any larger formal pedagogical research yet, I think it may be interesting to see even the partial results.

The difference between means is highly statistically significant. Further pedagogical research in this area should be done to get general conclusions, but these results seem to clearly indicate that the Heureka approach has a positive impact on the thinking abilities of students. 
Table 2: Results of the scientific reasoning test - Lower elementary school, Prague 6 (my classes)

\begin{tabular}{ccc}
\hline Year & $\begin{array}{c}\text { Number } \\
\text { of students }\end{array}$ & $\begin{array}{c}\text { Average number } \\
\text { of points }\end{array}$ \\
\hline 2010 & 23 & 14.7 \\
\hline 2011 & 21 & 12.5 \\
\hline 2012 & 20 & 13.1 \\
\hline 2013 & 29 & 14.8 \\
\hline
\end{tabular}

Table 3: Complete results of the scientific reasoning test (all groups)

\begin{tabular}{lccc}
\hline Group & $\begin{array}{c}\text { Number } \\
\text { of } \\
\text { students }\end{array}$ & $\begin{array}{c}\text { Average } \\
\text { number } \\
\text { of points }\end{array}$ & $\begin{array}{c}\text { Average } \\
\text { result } \\
\text { (in \%) }\end{array}$ \\
\hline All my students & 93 & 13.8 & $57.4 \%$ \\
\hline $\begin{array}{l}\text { All classes learned according to the } \\
\text { Heureka Project }\end{array}$ & 374 & 12.7 & $53.1 \%$ \\
\hline $\begin{array}{l}\text { Control group - students who did not } \\
\text { learn according to the Heureka }\end{array}$ & 521 & 8.9 & $37.1 \%$ \\
\hline
\end{tabular}

Table 4: Distribution of students on developmental-reasoning levels (Piaget)

\begin{tabular}{llcccc}
\hline \multirow{2}{*}{ Level } & \multicolumn{2}{c}{ Heureka group } & \multicolumn{2}{c}{ Control group } \\
\cline { 2 - 6 } & Number & in percents & Number & in percents \\
\hline $\mathbf{1}$ & $\begin{array}{l}\text { Concrete operational } \\
\text { level (0-8 points): }\end{array}$ & 87 & $23.3 \%$ & 278 & $53.4 \%$ \\
\hline $\mathbf{2}$ & $\begin{array}{l}\text { Transitional level } \\
\mathbf{( 9 - 1 6} \text { pts): }\end{array}$ & 196 & $52.4 \%$ & 200 & $38.4 \%$ \\
\hline $\mathbf{3}$ & $\begin{array}{l}\text { Formal } \text { operational } \\
\text { level (17-24 pts): }\end{array}$ & 91 & $24.3 \%$ & 43 & $8.3 \%$ \\
\hline
\end{tabular}

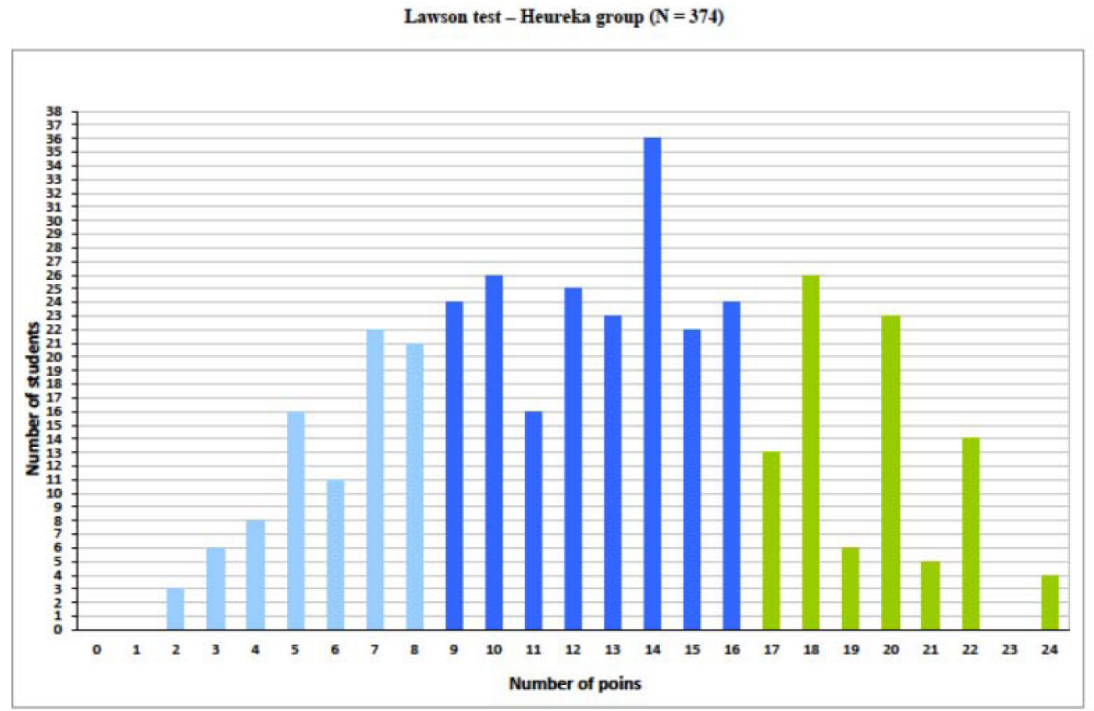

Figure 8: Results of the scientific reasoning test — The Heureka group 


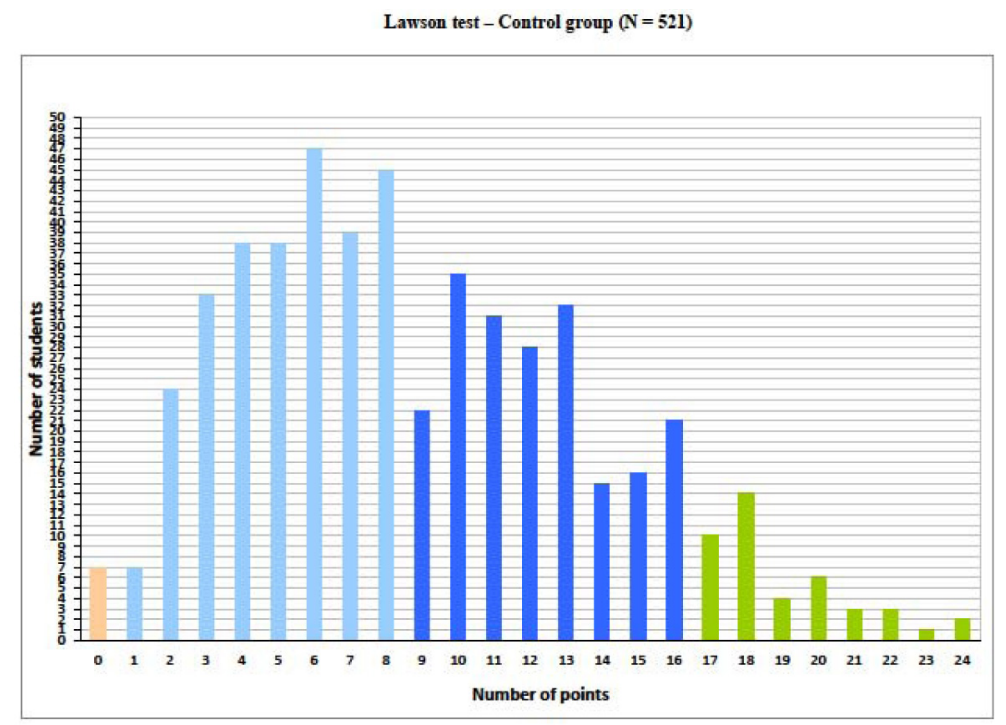

Figure 9: Results of the scientific reasoning test — The control group

\section{The SECOND MAIN PART OF ThE HeUREKA PROJECT - WORK WITH TEACHERS AND FUTURE TEACHERS}

The basic principles mentioned above we use not only in the work with students, but also in the work with teachers. Nowadays we consider teacher training to be the most important part of The Heureka Project.

We organize several types of seminars and prepare an annual conference. All seminars are completely voluntary; participants have no formal advantages or benefits at their schools. The only benefits are the teaching methods, plans of lectures, problems and tasks, etc., which they obtain during seminars. All are published on the internal web pages of the project. Examples of methodological materials were published also in journals and at web pages. All seminars are also free of charge. Our seminars take place in schools, so they are very informal. Participants sleep in their sleeping-bags in classrooms and they have to bring food with them (see Figure 10 and Figure 11). In spite of those conditions, we have more than 150 active participants, some of them even from Slovakia.

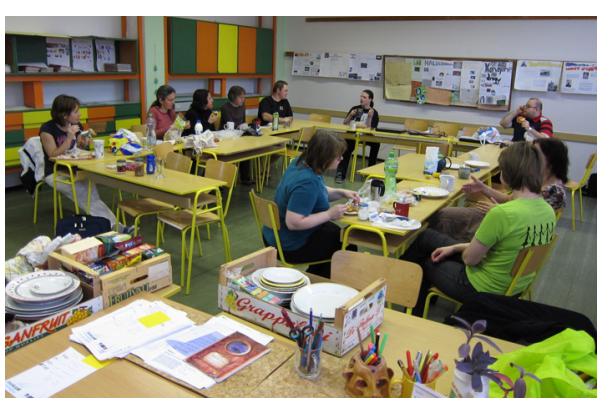

Figure 10: "The dining room"

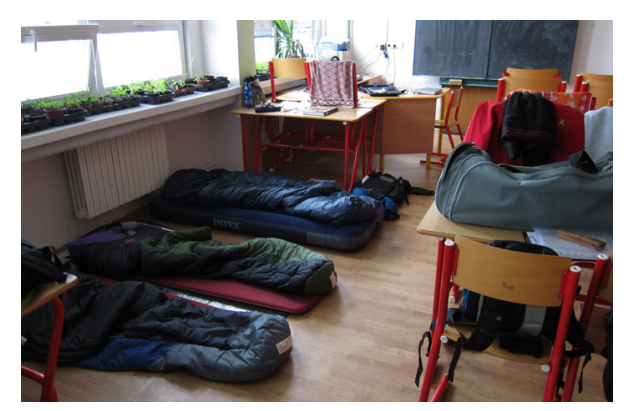

Figure 11: "The sleeping room" 


\subsection{SEMINARS FOR NEW PARTICIPANTS}

These seminars are intended for teachers who want to learn Heureka's teaching methods. Seminars are organized during weekends not to interfere with teachers' school work. The whole course consists of 10 weekend seminars during a two year period. Participants work at these seminars very similarly to students at school. They do experiments, solve problems, sometimes write tests, do voluntary homework, etc. (see Figure 12). Seminars are focused on:

- new approaches to teaching

- basic physics knowledge and its application

- personal development of participants

- games and other activities suitable for work with children

Besides this they discuss teaching methods they have seen and talk about pedagogical problems in their schools, too.
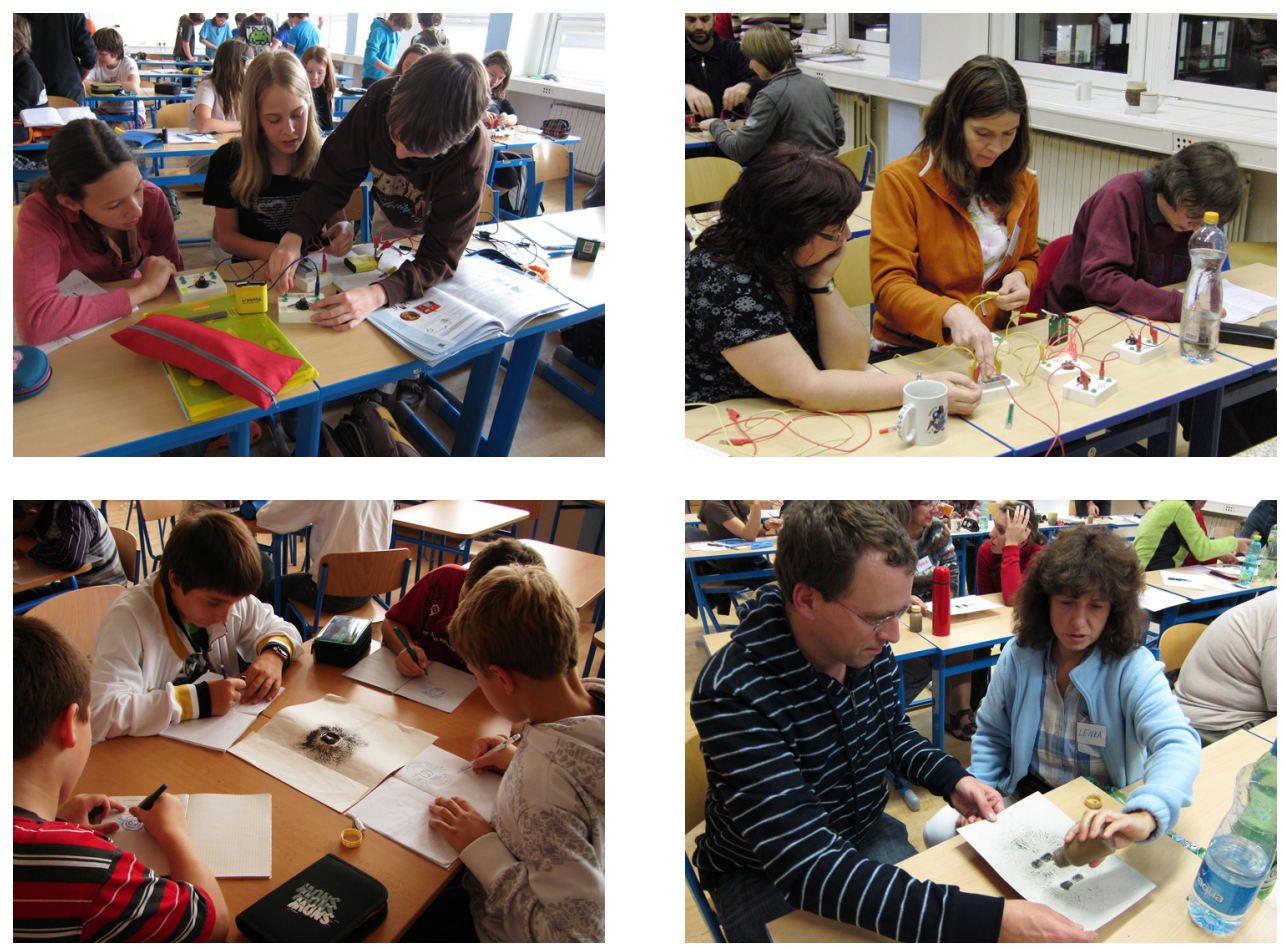

Figure 12: Teachers work at seminars similarly to students

To know more about the participants' opinions, we ask them to write a structured feedback at the end of every seminar. But maybe the best feedback is the fact that teachers continue to come to seminars and spend ten weekends with us. Based on the teachers' own feedback, we can say that the professional competencies of teachers are increasing during the seminars.

Apart from the structured feedback described above, we also ask teachers what they appreciate about these seminars. Twenty three teachers from the fourth course for new participants in 2008/2010 were asked what the attendance of these seminars had brought to them. During the last seminar of the course they completed a small questionnaire with nine open questions. (i.e.: "What changes have you found in your teaching during the last two years?", What have you learned in these seminars?", etc.). The essential part of their answers is summarized in Table 5. 
Benefits of the attendance in seminars

Number

\begin{tabular}{lc}
\hline Inspiration, getting manuals for teaching & of respondents \\
\hline Meeting with the same type of people, new friends & 23 \\
\hline I learned how to activate more students at school & 19 \\
\hline $\begin{array}{l}\text { I am more self-confident, I am not afraid to make } \\
\text { mistakes }\end{array}$ & 16 \\
\hline Improvement of knowledge of physics & 12 \\
\hline It "gives me energy" & 9 \\
\hline
\end{tabular}

Teachers called this course "the teachers' kindergarten", because we really start our work from the first lesson in the sixth grade, where children start learning physics, too. It could be unusual to teach physics from scratch teachers who graduated in universities. But in our experience many participants of our seminars are able to calculate difficult tasks but have difficulties with understanding some basic concepts.

We check these basic ideas using several conceptual problems in the test at the beginning of the first seminar. I recommend you to try to solve the four problems and write your solution before you will read the text further. Maybe you will better understand why our participants start to learn physics from scratch.

\section{TEST FOR NEW PARTICIPANTS (PART OF THE TEST)}

1. A car of mass $2500 \mathrm{~kg}$ goes up a hill (with a gradient $10 \%$ ) for two minutes at speed $50 \mathrm{~km} / \mathrm{h}$. A figure shows its position after one minute. Draw the net force (i.e. a sum of all forces) acting on the car.

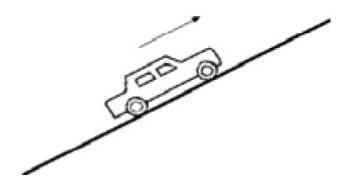

2. A figure shows a convex lens (a magnifying glass), positions of its focal points and a general ray approaching the lens. Draw the ray after it passes through the lens. (Find the precise solution, not any approximation).

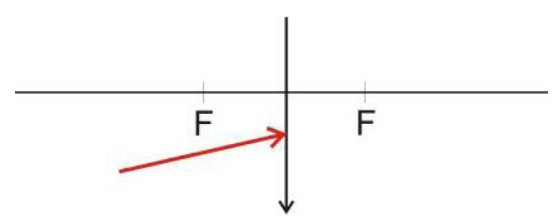

3. In a little pool, there is a small boat with an anchor inside the boat. We mark the level of water on the wall of the pool. How does this level change if we drop the anchor

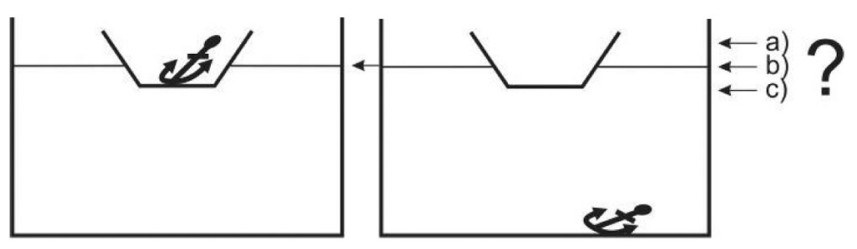
to the bottom of the pool?

Select the right variant and explain your reasoning:

a) The level of water rises.

b) The level stays the same.

c) The level of water falls. 
4. The first figure shows a pendulum hanging at rest. In the second figure, there is a moving pendulum shown just at the moment when it goes through the lowest point of its trajectory. Draw the net forces acting on the pendulum in both cases.

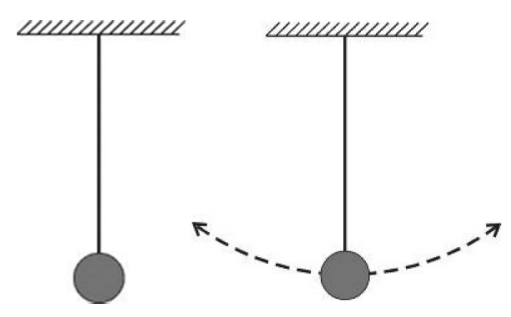

\section{THE SOLUTION OF THE TEST}

1. The car performs rectilinear motion with a constant velocity, so $F=0$ (the 1st Newton law).

2. Choose a source of the ray, find the image of the source, the general ray goes to this image after passing through the lens (as all other rays passing through the lens).

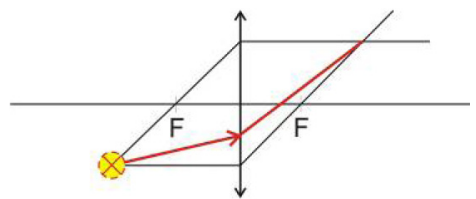

3. The experiment shows the result. As you can see on photos, the final level of water is lower than the initial.
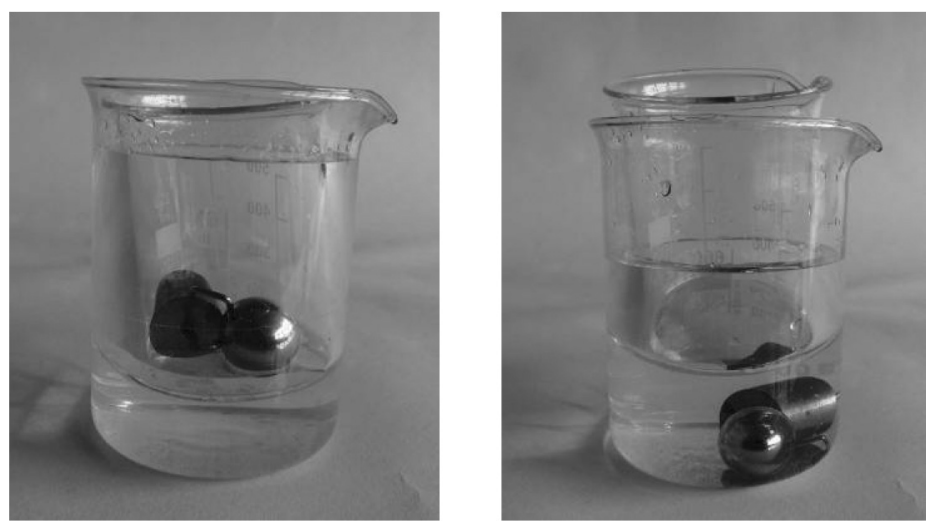

4. First situation - the pendulum is at rest, so the net force $F=0$ (The 1st Newton law). Second situation - the pendulum moves along the circle, the net force is centripetal.

We can therefore conclude - seminars for new participants allow teachers to:

- re-learn physics from the beginning

- get their own experience with active learning

- obtain experience with their own misconceptions

- achieve higher tolerance to students' mistakes during a teaching-learning process

- understand the necessity of a safe atmosphere in the classroom

\subsection{OTHER SEMINARS - FOR STUDENTS AND FOR MORE EXPERIENCED TEACHERS}

There are also seminars for students of our faculty (future teachers of mathematics and physics), who are interested in The Heureka Project. These seminars are organized very similarly to teachers' seminars for new participants, only not during weekends, but as a standard voluntary seminar (consecutive seminars in 4 terms, two hours per week). Usually more than $80 \%$ students from each year attend this seminar. 
We also organize seminars for experienced teacher who already finished "the teachers' kindergarten". Those seminars have usually one specific topic - e.g. Physics in Biology, History of Physics, Modern technology in the school, etc.

\section{THE HEUREKA WORKSHOPS}

"The Heureka Workshops" is an annual conference prepared both for physics teachers and for students - future physics teachers, who attend any of seminars of The Heureka Project, and for guests, too. There were about 130 participants (some of them with their children) in 2013.

To allow teachers to attend the conference without problems in their schools, we organize it during the weekend (usually the first weekend in October).

The characteristic attribute of this conference is its form. The whole conference is organized as a set of workshops (19 workshops were prepared in 2013; two of them were led in English by guests from abroad). There are no invited speakers, no lectures, and no formal meetings. Each workshop takes 90 minutes and repeats typically four times. The workshops are prepared and led by teachers from schools or from a university. The active work of participants is an essential requirement for each workshop. There are no other limitations. The topic could be a set of experiments, building some simple instrument, measurement of some properties of materials, games useful for physics teaching, etc. We built also Dancing bugs or Bridges from newspaper (Lipertova, 2011; Piskac, 2008) in the past. Every year we are surprised how many interesting ideas the teachers have.

As mentioned above, the conference is very informal. It takes place in the high school of a small town Nachod in East Bohemia, where one of the active teachers from The Heureka Project works. Participants sleep in classrooms in their sleeping bags, bring their own food, there is no welcome drink or conference dinner. Maybe this informal character supports the friendly atmosphere of this meeting. Teachers can talk to each other while eating or before sleeping, there are no formal barriers there.

We are pleased that guests from abroad come to Nachod every year in spite of the fact that the conference is conducted in the Czech language and living conditions are far from luxurious. According to our experience, there was never any problem with mutual understanding - either the head of the workshop is able to speak both Czech and English or somebody translates for a foreigner. Some of our guests described their experience and impressions from the conference in reports published in international journals (Swinbank, 2005; Planinsic, 2006; Milbrandt, 2010). We would like to invite readers who are interested to participate in next years' conferences which will be organized at the beginning of October each year.

\section{BONUS — WEIGHING USING A PIECE OF PAPER}

Finally I would like to present an excellent idea of Zdenek Polak, the local organizer of the conference The Heureka Workshops.

This is an example of the simplest scales, which are nevertheless able to weight with a considerable precision. This is a very nice application of the lever, that's why I usually use measuring with these scales as a labwork afterwards we learn about simple machines (a lever, a pulley, etc.). Children measure the mass of all Czech coins; they work individually, not in pairs. They fill in their results to the table 
on the blackboard (similarly as in the example concerning the pendulum mentioned above) and finally compare them with the official bank values.

You can determine the mass of a coin, a ring, etc. using only:

- a piece of paper

- a pin

- a ruler (for measuring the length)

\section{How TO GET A WEIGHT?}

On the package of printing paper it says that the square density of paper is $80 \mathrm{~g} / \mathrm{m}^{2}$. It means, that $1 \mathrm{~m}^{2}$ of paper (format A0) has a mass of $80 \mathrm{~g}$. One page of paper (format A4) is $1 / 16 \mathrm{~m}^{2}$, so its mass is $5 \mathrm{~g}$.

\section{HOW TO GET SCALES?}

You can fold your piece of paper several times (see Figure 13) to make scales.
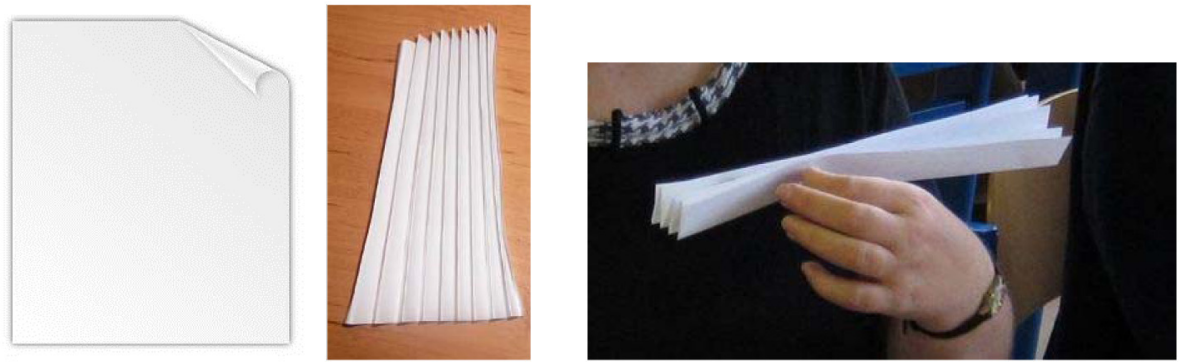

Figure 13: Making scales

\section{HOW TO MEASURE?}

Find the centre of mass of the paper (point $T$ ). Choose the point for an axis of rotation

( $A$, so $A$ is off-centre), the distance $a=|T A|$ should be about $4-5 \mathrm{~cm}$. Use a pin as an axis of rotation. Now you have a scales, where on one side (in the point $T$ ) is a mass of $5 \mathrm{~g}$ (mass of the paper), on the other side you will put a measured body. Put a coin (a ring, ... ) on scales, find its right place for equilibrium (see Figure 14). Measure the distance $(b)$ between the centre of measured body and the axis.

Figure 14: Equilibrium on scales

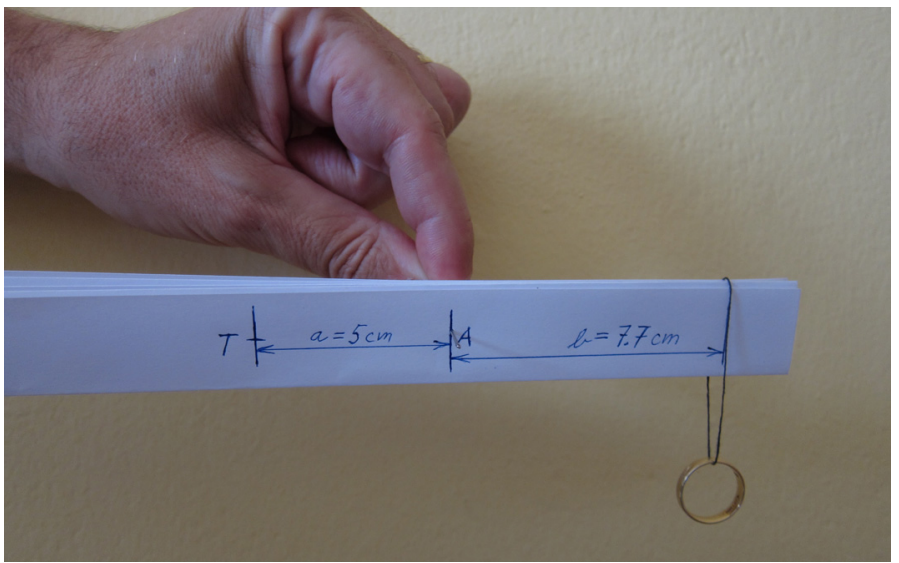


Calculate the equation of a lever:

$$
F_{1} \cdot a=F_{2} \cdot b
$$

For my ring this worked out as follows:

$$
\begin{aligned}
& \text { mass of the paper }=5 \mathrm{~g} \\
& \text { mass of the ring }=x \\
& \begin{array}{l}
a=5 \mathrm{~cm} \\
b=7.7 \mathrm{~cm} \\
5 \mathrm{~g} \cdot 5 \mathrm{~cm}=x \cdot 7.7 \mathrm{~cm} \\
x=25 / 7.7 \mathrm{~g}=3.2 \mathrm{~g}
\end{array}
\end{aligned}
$$

Using precision digital scales I found that the mass of my ring is $3.295 \mathrm{~g}$.

As you can see, this simple instrument is able to weight surprisingly precisely.

\section{Conclusion}

I described the history and the current state of The Heureka Project. Thanks to the recently acquired support of the Depositum Bonum Foundation, Heureka now has the opportunity to start a new stage of its development. The Foundation is seeking to improve science education in Czech elementary schools. One useful way of promoting this goal is to support physics teachers. With the new school year $(2013 / 2014)$ the Foundation and Heureka opened fifteen regional centres for physics teachers. The centres are led by teachers who have their own experience with Heureka and who are able to organize monthly meetings for other physics teachers in their regions. The main goal of the meetings is to support the professional development of teachers by giving them an opportunity to share their experience, learn about some new experiments and teaching approaches and borrow modern teaching tools. Built jointly by the Depositum Bonum Foundation and Heureka, the centres are firmly rooted in Heureka's principles which I have outlined above and which have brought tangible improvements into Czech classrooms.

After two decades of existence and growth, The Heureka Project is starting a new stage in its long-term evolution.

\section{REFERENCES}

Dewey, I. \& Dykstra, Jr. (2011). Physics Teaching and the Development of Reasoning. sciED, 2(2). Available at

http://www.scied.cz/Default.aspx?ClanekID=345\&PorZobr=1\&PolozkaID=132

Lawson, A.E. (1978a). The development and validation of a classroom test of formal reasoning. Journal of Research in Science Teaching, 15(1), 11-24.

Lawson, A. E., Karplus, R., \& Adi, H. (1978b). The development of propositional logic and formal operational schemata during adolescence. Journal of Research in Science Teaching, 15(6), 465-478. 
Lawson, A. E. \& Bealer, J. M. (1984). Cultural diversity and differences in formal reasoning ability. Journal of Research in Science Teaching, 21(7), 735-743.

Lawson, A.E. (1985). A review of research on formal reasoning and science teaching. Journal of Research in Science Teaching, 22(7), 569-618.

Lipertova, K. (2011). Dancing bugs. Available at http://www.youtube.com/watch?v=rf-QP0gfKiE and http://www.youtube.com/watch?v=AhTIQEgQeSE

Milbrandt, R. (2010). Innovative physics teaching conferences in the Czech Republic. The Physic Teacher, 48, p. 395-396.

Piskac, V. (2008). Bridges from newspaper. Available at http://www.youtube.com/watch? $\mathrm{v}=27 \mathrm{cbeFSi7}-\mathrm{M}$ and http://www.youtube.com/watch? $\mathrm{v}=\mathrm{rVCSObipAOM}$

Planinsic, G. (2006). Teachers share experiment know-how. Physics Education 41, p. $7-8$.

Renner, J. W., Lawson, A. E. (1973). Promoting Intellectual Development through Science Teaching. Physics Teacher, 273-276.

Svinbank, E. (2005). Reporting from a mattress in Nachod... Physics Education 40, p. 5.

IRENA DVOŘÁKOVÁ

Faculty of Mathematics and Physics, Charles University, Prague, and Junior Secondary School Cerveny vrch, Prague, Czech Republic 